\title{
Contribution of Non -Technical Skills on Nurses' Performance Efficiency of Nursing Care Process in Intensive Care Units
}

\section{Eman Abd EL Hady Elmohmady ${ }^{1}$, Reda Abd El-Fatah Abo Gad ${ }^{2}$, Amal Hamdy Abou $\operatorname{Ramadan}^{3}$}

B.Sc.N. - Faculty of Nursing ${ }^{1}$, Prof. of Nursing Services Administration, Faculty of Nursing, Tanta University ${ }^{2}$, Lecturer of Nursing Services Administration, Faculty of Nursing, Tanta University $^{3}$

\begin{abstract}
Background: Non-technical skills (NTS) are social, cognitive and personal skills that can enhance staff nurses to carry out technical skills, tasks and procedures. Aim: The study aimed to assess contribution of non-technical skills on nurses' performance efficiency of nursing care process in Intensive Care Units. Design: Descriptive correlation research design was used in the study. Setting: the study was conducted at El Mahala El-kobra General Hospital which affiliated to the Ministry of Health and Population. The subjects: all $(\mathrm{N}=200)$ available nurses at intensive care units who are working at the time of data collection were included in the study. Tools: Data was collected by using two tools. 1) Nurses' performance of nursing process observational checklist. 2) Non-technical skills of nurses' questionnaire. Results: The result showed that more than two- thirds $(71.0 \%)$ of nurses had satisfied level in performing total technical skills and less than two -thirds (63\%) of nurses had satisfied level in total non technical skills. Conclusion: There was significant positive correlation between overall observed nurses' technical skills and their overall non-technical skills. Recommendation: establishing specific unit policies, procedures and standards of nursing technical and nontechnical skills, conducting training programs to cover all technical and non-technical skills, and integrate non-technical skills into the nursing curriculum.
\end{abstract}

Keywords: Intensive Care Unit, Nursing process, Non- technical skills, Technical skills 


\section{Tanta Scientific Nursing Journal}

\section{Introduction}

Nurses play a key role in the healthcare field because they provide nursing care to patients ${ }^{(1)}$. Nursing care, especially in Intensive Care Units (ICUs), needs constant awareness and vigilance because the nurses provide critical care and living support for acutely unwell and vigilance because the nurses provide critical care and living support for acutely unwell and injured patients ${ }^{(2,3)}$. The patients in ICUs are completely depending on care givers so that, the nurses' knowledge, attitude, and practices have an impact on the patients' recovery to a greater extent ${ }^{(4) .}$ Care is the reason for the existence of the nursing profession and is a global concept of nursing and the nursing process used to ensure this care ${ }^{(5)}$. Ferreiral $(2018)^{(6)}$ said that Wanda Horta (1979) developed the first generation of nursing process supported by the theory of basic human needs based on Maslow's theory of human motivation and enhancing the importance of human care. Nursing process is a scientific method for directing procedures and qualifying nursing care. Recently, the process has been defined as a systematic and dynamic method of delivering nursing care, and it works through six interrelated steps: assessment, diagnosis, planning, implementation, evaluation and documentation $^{(7) \text {. }}$
Assessment is an organized process that involves collecting and arranging data in a systematic and retrievable manner. Subjective and objective data are collected from multiple sources. The nurse focuses on creating a patient profile to present a picture of the patient that includes the patients' physical, psychological, social, developmental, spiritual and cultural needs ${ }^{(8)}$. Nursing diagnosis is a clinical judgment on patients' responses to actual or potential health problems ${ }^{\left({ }^{(9)}\right.}$ It is the scientific interpretations of the data gathered from the assessment that drive the planning and implementation of interventions to achieve the best results in health field. Likewise, it constitutes the essential elements of evidence-based nursing care, taking into account patients' needs and safety ${ }^{(10)}$. Planning includes setting priorities, setting goals, looking at the best for patients, and defining accurate nursing interventions. Implementation occurs when care plan is putting into action, and the nurse makes the planned interventions ${ }^{(11)}$. The evaluation is carried out by observing the patients' progress toward achieving the known results and observing the patients' reaction to efficiency of nursing interventions for the reason of changing the plan as described (12). 


\section{Tanta Scientific Nursing Journal}

In this regard, nursing documents must be completed to the top standards, to achieve the safety and quality of healthcare. It can be either paper or organized within the system known as the electronic health records ${ }^{(13)}$. The information in nursing documentation reflects the full series of nursing operations that range from nursing assessments, diagnosis, nursing interventions or implementation and evaluation of nursing care, and, ultimately, to patients' response and outcomes ${ }^{(14) .}$

Nursing process improves patients' care, stimulates building theoretical, scientific knowledge and systematizes nursing care $^{(15)}$. Nursing care systematization is referred to as a method that can improve the quality of nursing care because it gives support, safety and guidance for nursing work. So for implementation of nursing care process by successful way, nurses need non-technical skills that affect their performance $^{(16,17)}$. Non - technical skills in the health care setting defined as a collection of skills that lead to achieve high quality, safe, effective, and optimum outcomes for efficient professional care in healthcare system ${ }^{(18)}$. It includes cognitive skills (decision-making) and socials networks skills (teamwork, communication, and leadership) (19). Decision making is a process that involves options. Through this process, nurses can identify problems, create alternatives, evaluate alternatives, choose an alternative, implement the decision, and assess the effectiveness of decision ${ }^{(20)}$.

Teamwork is not always about working in big teams, but feeling of togetherness that creates good environment. Teamwork improves nurses' performance by putting lots of ideas on table to choose the best one $^{(21) .}$ Communication is not only oral or written, but also, includes body language, motivation, source of information, helps in socializing, and controlling process. Bad communication in healthcare leads to incomplete patient assessment, misdiagnosis, care omission, delayed treatment, medication errors, patients' injury, or death ${ }^{(22)}$. Finally, leadership is defined as the process of influencing nurses to achieve best outcome. ${ }^{(23)}$.

A true nurse leader has ability to achieve mission, goals, and responsibility ${ }^{(24)}$ Good nurse leadership has positive impact on nurses' work and patients' safety ${ }^{(25) .}$

Significance of the study

Lack the non -technical skills leads to errors and negative events. Studies show that $50-80 \%$ of care errors or adverse events are caused by human behavior associated non-technical skills ${ }^{(26,27)}$. These skills are an integral part of clinical nursing competence. It enhances patients' 
assessment, nursing performance, and outcomes ${ }^{(28,29)}$. It also appears necessary to effectively manage nursing risks and improves nurses' behaviors towards

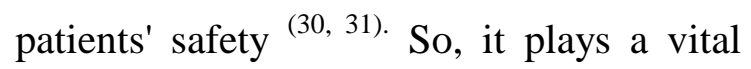
role in effective nursing practice ${ }^{(32) .}$

\section{Aim of the study}

The aim of present study was to:

Assess contribution of non-technical skills on nurses' performance efficiency of nursing care process in Intensive Care Units

\section{Research questions}

1. What are nurses' technical performance levels in intensive care unit?

2. What are nurses' non-technical performance levels in intensive care unit?

3. What is the contribution of nontechnical skills on nurses' performance efficiency of nursing care process in intensive care units?

\section{Subjects and Method}

Study design: Descriptive correlation research design was used in the present study to achieve the aim of the study.

Setting: The study was conducted in all intensive care units at El Mahala El-kobra General Hospital affiliated to the Ministry of Health and Population.

\section{Subjects:}

The study subjects included all $(\mathrm{N}=200)$ available nurses at intensive care units.
They divided as follow ; 30 nurse at Cardiac Care Unit, 30 nurse at Pediatric Intensive Care Unit, 35 nurse at Medical Care Unit, 35 nurse at Surgical Care Unit and 70 nurse at Neonatal Intensive Care unit working at El Mahala El-kobra General Hospital at the time of data collection.

\section{Tools of data collection:}

To achieve the aim of the study two tools were used

\section{Tool (I): Nurses' performance of} nursing process observational checklist

This tool developed by researcher based on Poortaghi et al., (2015) ${ }^{(33)}$ and recent related literature ${ }^{(34,35)}$. It was used to assess nurses' performance of nursing process. It consisted of two parts as follow;

Part one: included subject identification data such as nurses' code and department Part two: Nurses' technical performance. It was consisted of six nursing process domains as follow;

- Assessment consisted of 6 items

- Nursing diagnoses consisted of 5 items

- Planning consisted of 10 items

- Implementation include 3dimensions

a) Nursing care ( 22 items)

b) Teaching (7 items)

c) Relation and communication (4 items)

- Evaluation consisted of 8 items

- Documentation consisted of 9 items 


\section{Scoring system:}

Nurses' performance was observed by three points Likert Scale ranging from not done (1), done (2), and completely done (3). The total score was calculated by summing score of all categories. The total score statistically represented varying levels of nurses' technical performance as follow;

- Satisfied level of technical skill $\geq 65 \%$

- Unsatisfied level of technical skill< $65 \%$

Tool (II): Non-technical skills of nurses'

\section{questionnaire}

This tool was developed by researcher based on Cooper et al., (2010) ${ }^{(36)}$ and recent related literature (37-40) and used to assess non-technical skills of nurses. It consisted of two parts as follow;

Part (I): Nurses' characteristics data such as age, gender, type of ICU, years of experience, educational level and marital status

Part (II): The non-technical skills of nurses' questionnaire included four subscales as follow:

- Decision making subscale (9 items)

- Team dynamics subscale (15 items)

- Communication subscale (12items).

- Leadership behavior subscale(21 items)

Scoring system:

Nurses' response measured on five points

Likert Scale ranging from (1) strongly disagree, (2) disagree, (3) uncertain, (4) agree, and (5) strongly agree which concluded into three points scaling namely agree, uncertain, and disagree. The total score calculated by summing score of all categories. The total score statistically represented varying levels of staff nurses' non-technical skills as follow:

- Satisfied level of non-technical skill $\geq 65 \%$

-Unsatisfied level of non-technical skill $<65 \%$

\section{Method}

1- Official permission was obtained from the responsible authorities.

2- The aim of the study explained to nurses to gain their cooperation

3- Ethical and legal consideration:

- Approval of ethical committee at faculty of nursing was obtained

- The researcher introduced herself to the participant, and nurses' informed consent for participation in the study was obtained.

- Nurses were informed about the privacy and confidentiality information obtained from them, nature of the study was not produced harm for them and the right to withdraw was reserved.

- Nurses was not informed to be observed 
4- The study tools were modified by the researcher based on recent related literatures.

5- Nurses' performance of nursing process observational checklist (tool I) was used to assess nurses' performance of nursing process and non-technical skills of nurses' questionnaire (tool II) was used to assess non-technical skills of nurses.

6- The tools were translated into Arabic language and reviewed by the supervisors then submitted to six experts to check content validity and clarity of the tools. The experts were; three assistant professor of Nursing Administration and one lecturer of Nursing Administration. Also, two assistant professor of Medical-surgical nursing, Faculty of Nursing, Tanta University. The experts' responses were represented in four points rating scale (4-1) ranging from4=strongly relevant, $3=$ relevant, $2=$ little relevant, and $1=$ no relevant. Necessary adjustments have been made including; Clarification, deletion of some elements, simplification of words, and review the correct translation and spelling of some words. The face validity value of tool (I): Nurses' performance of nursing process observational checklist was
96.64\%.A tool (II) non-technical skill of nurses' questionnaire was $97.82 \%$.

7- A pilot study was carried out on a sample $(10 \%)$

8- of nurses $(n=20)$. they were not excluded from the main study sample. A pilot study was carried out after the experts' opinion and before starting the actual data collection. The aim of pilot study was to test the tool for its reliability, clarity, the sequence of items, applicability and relevance of items. Pilot study also served to estimate the time required for filling the questionnaire sheet from nurses was 20-30 minutes. Minor modification was done on the tools.

9- Reliability of tools was tested using Cronbach Alpha Coefficient test. Reliability of tool (I) nurses' performance of nursing process observational checklist was0.999, and reliability of tool (II) non-technical skills of nurses' questionnaire was 0.998 .

10- Data collection phase: The researcher was observed the nurses during their activities (nursing process) three times during their shifts work using tool (I) to assess their technical nursing process performance. The researcher met the respondents' nurses in small groups at their work settings and 
distributed the tool (II). The subjects recorded answers in the presence of the researcher to clarify and ascertain that all questions were answered. Data was collected through out six months.

\section{Statistical analysis:}

The collected data were organized, tabulated and statistically analyzed using Microsoft office excel and IBM SPSS software package version 20.0. (Armonk, NY: IBM Corp). Qualitative data were described using number and percent. Quantitative data were described using range (minimum and maximum), mean, and standard deviation. Significance of the obtained results was judged at or less than the 5\% level and used Pearson coefficient (r) to measures linear correlation between two the studied variables. The used tests were 1) Chi-square test $(\chi 2)$ was done for comparison between two groups and more and used Monte Carlo (MC) method for correction

\section{Results}

Table (1): Illustrates percentage distribution of nurses according to their personal characteristics data. The age of nurses ranged between 21-35 years with mean score $27.06 \pm 3.40$. More than half (51.5\%) of nurses were aged 25-30 years old, while only $21.0 \%$ of them were aged $<25$ years old. Majority $(82.0 \%)$ of nurses were female and only $18.0 \%$ of them were male. Regarding to nurses' years of experience, the mean years of experience was $4.74 \pm 3.26$, more than half $(56.5 \%)$ of nurses had less than 5 years of experience and slightly one- third $(33.5 \%)$ of nurses had 5-10 years of experience. Regarding to educational level, nearly two - thirds $(66.0 \%)$ of nurses had bachelor of nursing, and about one-third (30.0\%) of them had technical institute of nursing. Regarding to type of ICU, over one- third (34.5\%)of nurses working at neonatal ICU, $17.5 \%$ of nurses are working at Medical ICU, $18.0 \%$ of nurses working at surgical ICU and equal percent (15.0\%) of them are working at Cardiac and pediatric ICU.

Figure (1): Demonstrates that more than two- thirds of nurses had satisfied level in performing overall nursing care process, while, the rest of nurses had unsatisfied level in performing nursing care process as total.

Figure (2): Show that less than two -thirds of nurses had satisfied level in total non technical skills. While, more than one third of nurses had unsatisfied level in non -technical skills as total.

Table (2): Reveals mean score, standard deviation, percentage and ranking of observed nurses' performance of nursing care process. Mean percent score of overall mean performance was $(77.15 \pm 33.35)$. 
The highest percent score $(82.20 \pm 30.43)$ was for nursing diagnosis followed by documentation (81.03 \pm 28.48$)$, and relation and communication (79.88 \pm 32.91). While, the lowest percent score (68.61 \pm 40.97) was for teaching domain of nurses' technical performance.

Table (3): Shows mean score, percent score, standard deviation and ranking of overall mean nurses' non-technical skills items. Percent score of nurses' nontechnical skills was $71.75 \pm 31.99$. The highest percent score $(73.64 \pm 28.96)$ was for decision making skills followed by communication competence skills (72.42 \pm 32.18 ) and, team dynamic skills (72.16 \pm 33.26). While, the lowest percent score (70.26 \pm 32.48) was for leadership behavior skills.

Figure (3): Shows correlation between nurses overall nursing care process and their non-technical skills. There were significant positive correlation between overall observed nurses' technical skills and their overall non-technical skills. $(r=0.346, p<0.001 *)$.

Table (4): Demonstrates relation between nurses' overall performance of nursing care process and their characteristics data. There were significant relations between nurses' performance of all items of nursing care process skills and their personal characteristic data at $\mathrm{p} \leq 0.05$.

Table (5): Demonstrates relation between nurses' non-technical skills and their characteristics data. There were significant relations between nurses' non- technical skill and all their characteristics data at $\mathrm{p} \leq$ 0.05 except gender $(\chi 2=0.015, \mathrm{P}=0.903)$. 
Table (1): Percentage distribution of nurses according to their personal characteristics data $(\mathrm{N}=\mathbf{2 0 0})$

\begin{tabular}{|c|c|c|}
\hline Nurses' characteristics data & $\mathbf{N}$ & $\%$ \\
\hline -Age & & \\
\hline$<25$ & 42 & 21.0 \\
\hline $25-30$ & 103 & 51.5 \\
\hline$\geq 30$ & 55 & 27.5 \\
\hline Min. - Max (Range) & \multirow{2}{*}{\multicolumn{2}{|c|}{$\begin{array}{c}21.0-35.0 \\
27.06 \pm 3.40\end{array}$}} \\
\hline Mean $\pm \mathrm{SD}$ & & \\
\hline \\
\hline Female & 164 & 82.0 \\
\hline Male & 36 & 18.0 \\
\hline \multicolumn{3}{|l|}{-Years of Experiences } \\
\hline$<5$ & 113 & 56.5 \\
\hline $5-10$ & 67 & 33.5 \\
\hline$\geq 10$ & 20 & 10.0 \\
\hline Min. - Max (Range) & \multirow{2}{*}{\multicolumn{2}{|c|}{$\begin{array}{c}1.0-15.0 \\
4.74 \pm 3.26\end{array}$}} \\
\hline Mean \pm SD & & \\
\hline \\
\hline Secondary nursing school & 6 & 3.0 \\
\hline Technical institute of nursing & 60 & 30.0 \\
\hline Bachelor of nursing & 132 & 66.0 \\
\hline Master of nursing & 2 & 1.0 \\
\hline \multicolumn{3}{|l|}{-Marital status } \\
\hline Married & 150 & 75.0 \\
\hline Not married & 50 & 25.0 \\
\hline \multicolumn{3}{|l|}{-Type of ICU } \\
\hline Neonatal & 69 & 34.5 \\
\hline Medical & 35 & 17.5 \\
\hline Surgical & 36 & 18.0 \\
\hline Cardiac & 30 & 15.0 \\
\hline Pediatric & 30 & 15.0 \\
\hline
\end{tabular}




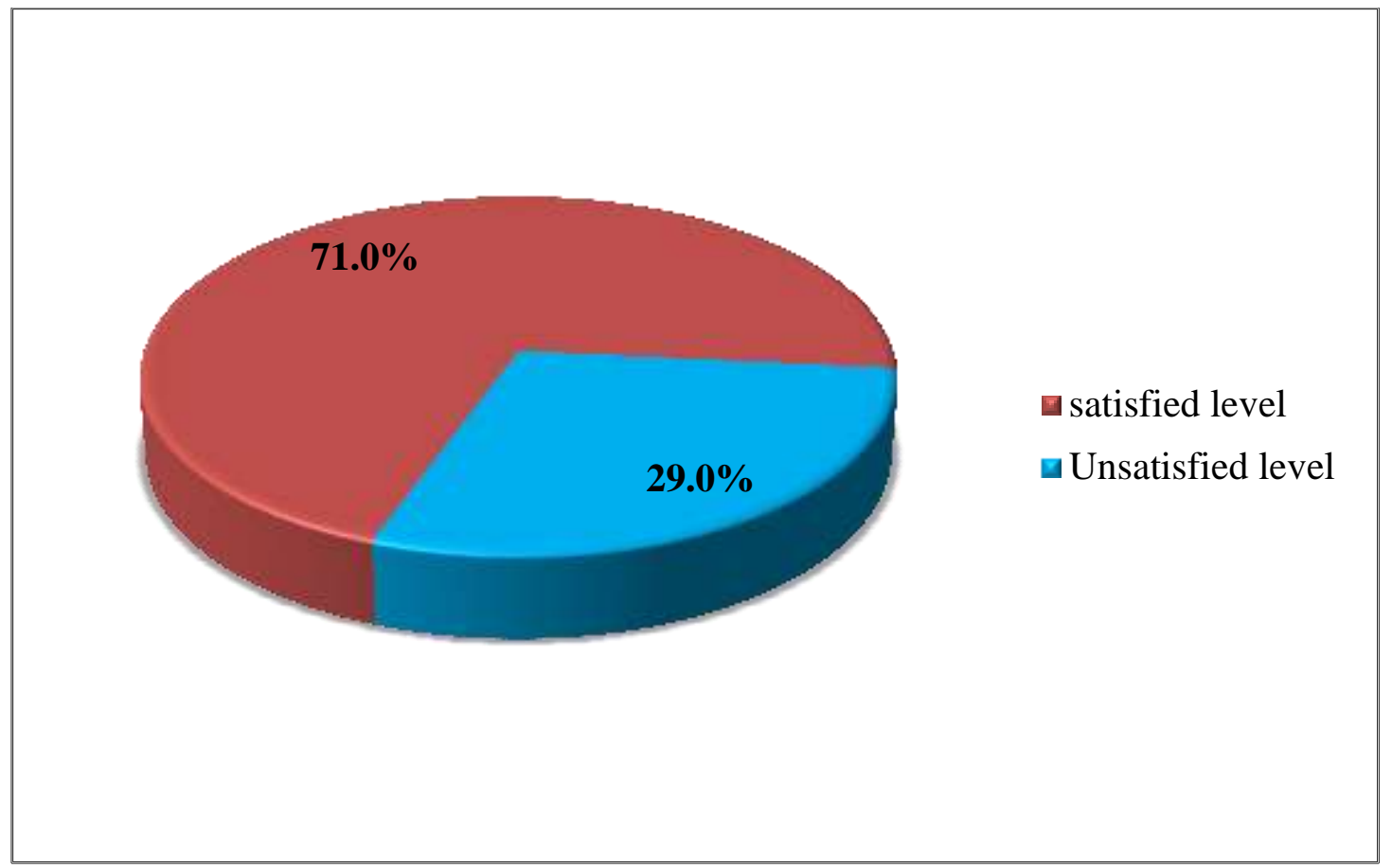

Figure (1): Levels of nurses' total nursing care process performance skills $(\mathrm{N}=\mathbf{2 0 0})$

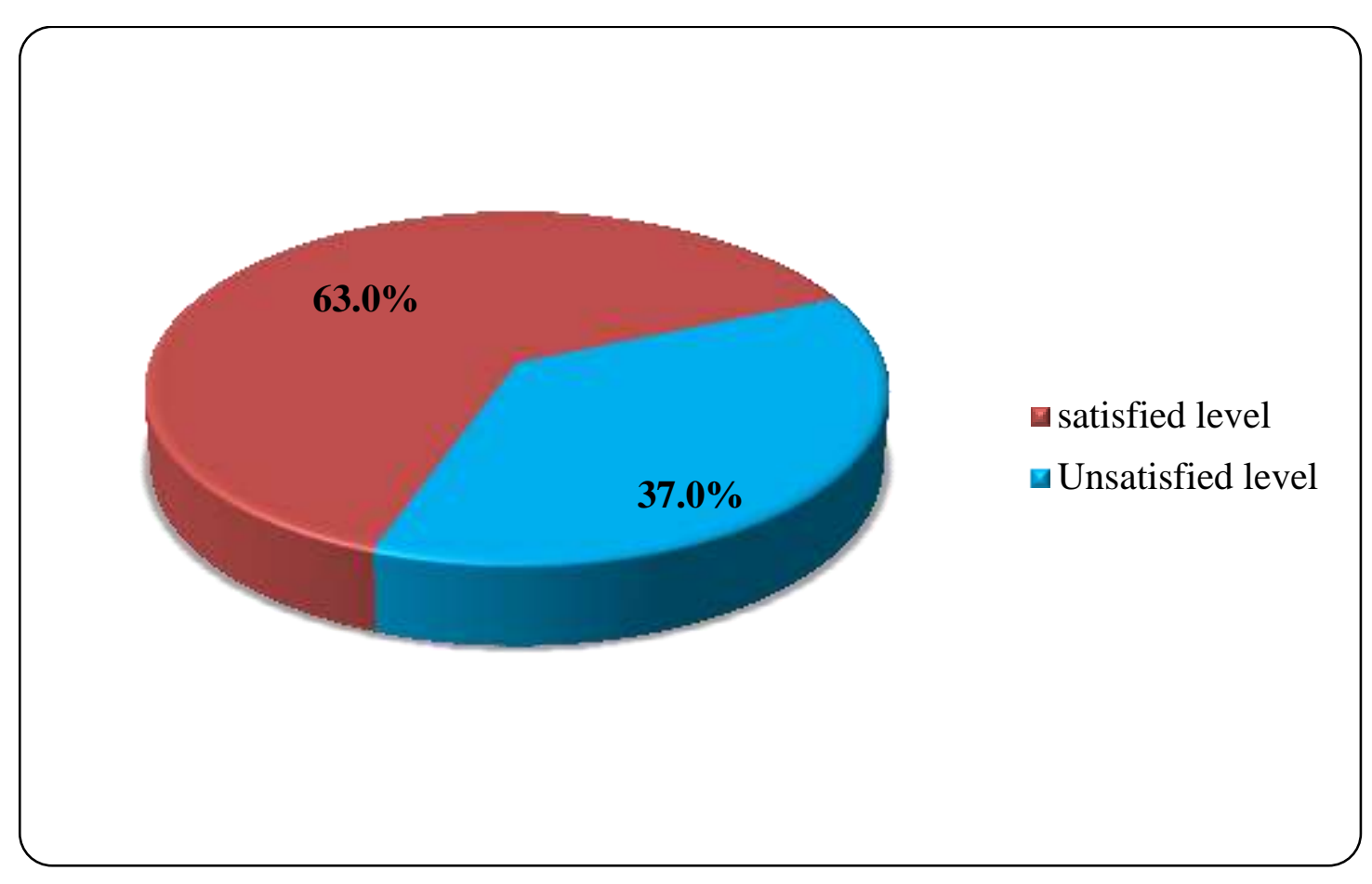

Figure (2): Levels of nurses' total non-technical skills $(\mathrm{N}=200)$ 
Table (2): Mean score, standard deviation, and ranking of observed nurses' performance of nursing care process items $(\mathbf{N}=200)$

\begin{tabular}{|l|c|c|c|}
\hline \multirow{2}{*}{ Nursing process items } & \multicolumn{3}{|c|}{ Observation of nurses' technical } \\
& \multicolumn{2}{|c|}{ performance } \\
\cline { 2 - 4 } & Total score & Percent score & Ranking \\
\hline Assessment & $27.0-9.0$ & $100.0-0.0$ & $\mathbf{6}$ \\
Min. - Max. & $6.07 \pm 22.83$ & $76.81 \pm 33.72$ & \\
Mean \pm SD. & $15.0-5.0$ & $100.0-0.0$ & $\mathbf{1}$ \\
\hline Nursing diagnosis & $3.04 \pm 13.22$ & $82.20 \pm 30.20$ & \\
Min. - Max. & & & \\
Mean \pm SD. & $30.0-10.0$ & $100.0-0.0$ & $\mathbf{4}$ \\
\hline Planning & $6.61 \pm 25.79$ & $78.95 \pm 33.07$ & \\
Min. - Max. & & & \\
Mean \pm SD. & $66.0-22.0$ & $100.0-0.0$ & $\mathbf{7}$ \\
\hline Implementation & $15.11 \pm 55.41$ & $5.92 . \pm 34.35$ & \\
a Nursing care & & & \\
Min. - Max. & $21.0-7.0$ & $100.0-0.0$ & $\mathbf{8}$ \\
Mean \pm SD. & $5.74 \pm 16.61$ & $68.61 \pm 40.97$ & \\
\hline b )Teaching & & & \\
Min. - Max. & $12.0-4.0$ & $100.0-0.0$ & $\mathbf{3}$ \\
Mean \pm SD. & $2.63 \pm 10.39$ & $79.88 \pm 32.91$ & \\
\hline c)Relations and & & & \\
communication & $24.0-8.0$ & $100.0-0.0$ & $\mathbf{5}$ \\
Min. - Max. & $5.49 \pm 20.36$ & $77.22 \pm 34.31$ & \\
Mean \pm SD. & $27.0-9.0$ & $100.0-0.0$ & $\mathbf{2}$ \\
\hline Evaluation & $5.13 \pm 23.58$ & $81.03 \pm 28.48$ & \\
Min. - Max. & $22.0-74.0$ & $100.0-0.0$ & - \\
Mean \pm SD. & $49.36 \pm 188.17$ & $77.15 \pm 33.35$ & \\
\hline Documentation & & & \\
Min. - Max. & & & \\
Mean \pm SD. & & & \\
\hline Overall performance & & & \\
Min. - Max. & & & \\
Mean \pm SD. & & & \\
\hline
\end{tabular}


Table (3): Mean score, standard deviation and ranking of nurses' nontechnical skills items $(\mathrm{N}=200)$

\begin{tabular}{|l|c|c|c|}
\hline \multicolumn{1}{|c|}{ Non-technical skills } & \multicolumn{3}{|c|}{ Nurses' non-technical skills } \\
\hline \multicolumn{1}{|c|}{ Items } & Total score & Percent score & Ranking \\
\hline $\begin{array}{l}\text { Decision making } \\
\text { Min. - Max. }\end{array}$ & $11.0-45.0$ & $5.56-100.0$ & $\mathbf{1}$ \\
Mean \pm SD. & $35.51 \pm 10.43$ & $73.64 \pm 28.96$ & \\
\hline $\begin{array}{l}\text { Team Dynamics } \\
\text { Min. - Max. }\end{array}$ & $16.0-75.0$ & $1.67-100.0$ & $\mathbf{3}$ \\
Mean \pm SD. & $58.30 \pm 19.96$ & $72.16 \pm 33.26$ & \\
\hline $\begin{array}{l}\text { Communication competence } \\
\text { Min. - Max. }\end{array}$ & $14.0-60.0$ & $4.17-100.0$ & $\mathbf{2}$ \\
Mean \pm SD. & $46.76 \pm 15.45$ & $72.42 \pm 32.18$ & \\
\hline Leadership behavior & & & \\
Min. - Max. & $21.0-105.0$ & $0.0-100.0$ & $\mathbf{4}$ \\
Mean \pm SD. & $80.02 \pm 27.28$ & $70.26 \pm 32.48$ & \\
\hline $\begin{array}{l}\text { Overall Non-technical skills } \\
\text { Min. - Max. }\end{array}$ & $62.0-285.0$ & $2.19-100.0$ & $\mathbf{-}$ \\
$\quad$ Mean \pm SD. & $220.59 \pm 72.95$ & $71.75 \pm 31.99$ & \\
\hline
\end{tabular}

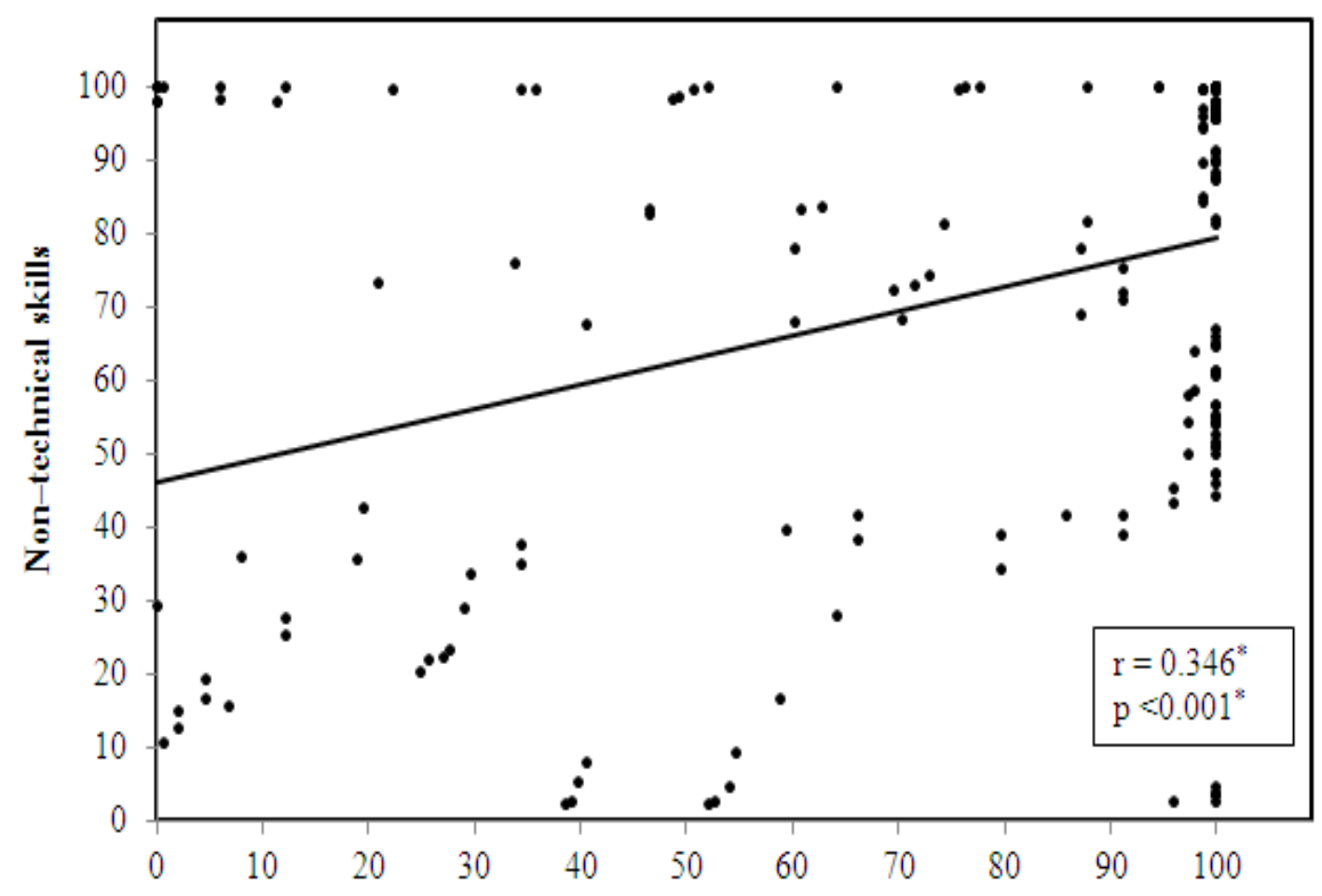

Technical skills

Figure (3): Correlation between nurses' overall nursing care process and their non-technical skills 
Table (4): Relation between nurses' overall nursing care process performance skills and their characteristics data

\begin{tabular}{|c|c|c|c|c|c|c|}
\hline \multirow{3}{*}{$\begin{array}{l}\text { Nurses' } \\
\text { items }\end{array}$} & \multicolumn{4}{|c|}{$\begin{array}{l}\text { Overall nursing care process } \\
\text { performance }\end{array}$} & \multirow{3}{*}{$\chi^{2}$} & \multirow{3}{*}{$\mathbf{P}$} \\
\hline & \multicolumn{2}{|c|}{$\begin{array}{c}\text { Unsatisfied } \\
\text { level } \\
(<65 \%) \\
(\mathrm{N}=58)\end{array}$} & \multicolumn{2}{|c|}{$\begin{array}{c}\text { Satisfied } \\
\text { level } \\
(>65 \%) \\
(N=142)\end{array}$} & & \\
\hline & $\mathbf{n}$ & $\%$ & $\mathrm{n}$ & $\%$ & & \\
\hline \multicolumn{7}{|l|}{ Age } \\
\hline$<25$ & 25 & 43.1 & 17 & 12.0 & \multirow{3}{*}{$24.895^{*}$} & \multirow{3}{*}{$<0.001^{*}$} \\
\hline $25-30$ & 24 & 41.4 & 79 & 55.6 & & \\
\hline$\geq 30$ & 9 & 15.5 & 46 & 32.4 & & \\
\hline \multicolumn{7}{|l|}{ Gender } \\
\hline Female & 42 & 72.4 & 122 & 85.9 & \multirow{2}{*}{$5.086^{*}$} & \multirow{2}{*}{$0.024^{*}$} \\
\hline Male & 16 & 27.6 & 20 & 14.1 & & \\
\hline \multicolumn{7}{|l|}{ Type of ICU } \\
\hline Neonatal & 13 & 22.4 & 56 & 39.4 & \multirow{5}{*}{$18.235^{*}$} & \multirow{5}{*}{$0.001^{*}$} \\
\hline Medical & 16 & 27.6 & 19 & 13.4 & & \\
\hline Surgical & 10 & 17.2 & 26 & 18.3 & & \\
\hline Cardiac & 15 & 25.9 & 15 & 10.6 & & \\
\hline Pediatric & 4 & 6.9 & 26 & 18.3 & & \\
\hline \multicolumn{7}{|l|}{ Years of Experiences } \\
\hline$<5$ & 41 & 70.7 & 72 & 50.7 & \multirow{3}{*}{$9.359^{*}$} & \multirow{3}{*}{$0.009^{*}$} \\
\hline $5-10$ & 16 & 27.6 & 51 & 35.9 & & \\
\hline$\geq 10$ & 1 & 1.7 & 19 & 13.4 & & \\
\hline \multicolumn{7}{|l|}{ Educational level } \\
\hline Secondary nursing school & 4 & 6.9 & 2 & 1.4 & \multirow{4}{*}{$18.482^{*}$} & \multirow{4}{*}{${ }_{<0.001}^{\mathrm{MC}_{\mathrm{p}}}$} \\
\hline $\begin{array}{l}\text { Technical institute of } \\
\text { nursing }\end{array}$ & 28 & 48.3 & 32 & 22.5 & & \\
\hline Bachelor of nursing & 26 & 44.8 & 106 & 74.6 & & \\
\hline Master of nursing & 0 & 0.0 & 2 & 1.4 & & \\
\hline \multicolumn{7}{|l|}{ Marital status } \\
\hline Married & 29 & 50.0 & 121 & 85.2 & \multirow{2}{*}{$27.230^{*}$} & \multirow{2}{*}{$<0.001^{*}$} \\
\hline Not married & 29 & 50.0 & 21 & 14.8 & & \\
\hline
\end{tabular}

$\chi^{2}$ :Chi square test MC:Monte Carlo

p: $p$ value for association between the studied categories

$*$ : Statistically significant at $\mathbf{p} \leq \mathbf{0 . 0 5}$ 
Table (5): Relation between nurses' overall non-technical skills and their characteristics data

\begin{tabular}{|c|c|c|c|c|c|c|}
\hline \multirow{3}{*}{ Nurses' characteristics items } & \multicolumn{4}{|c|}{ Overall non- technical skills } & \multirow{3}{*}{$\chi^{2}$} & \multirow{3}{*}{$\mathbf{P}$} \\
\hline & \multicolumn{2}{|c|}{  } & \multicolumn{2}{|c|}{$\begin{array}{c}\text { Satisfied } \\
\text { level } \\
(>65 \%) \\
(\mathbf{N}=126) \\
\end{array}$} & & \\
\hline & $\mathbf{N}$ & $\%$ & $\mathbf{n}$ & $\%$ & & \\
\hline \multicolumn{7}{|l|}{ Age } \\
\hline$<25$ & 24 & 32.4 & 18 & 14.3 & \multirow{3}{*}{$14.458^{*}$} & \multirow{3}{*}{$<0.001^{*}$} \\
\hline $25-30$ & 26 & 35.1 & 77 & 61.1 & & \\
\hline$\geq 30$ & 24 & 32.4 & 31 & 24.6 & & \\
\hline Gender & 61 & 82.4 & 103 & 81.7 & & \\
\hline $\begin{array}{l}\text { Female } \\
\text { Male }\end{array}$ & 13 & 17.6 & 23 & 18.3 & 0.015 & 0.903 \\
\hline \multicolumn{5}{|l|}{ Type of ICU } & \multirow{6}{*}{$56.957^{*}$} & \multirow{6}{*}{$<0.001^{*}$} \\
\hline Neonatal & 29 & 39.2 & 40 & 31.7 & & \\
\hline Medical & 4 & 5.4 & 31 & 24.6 & & \\
\hline Surgical & 14 & 18.9 & 22 & 17.5 & & \\
\hline Cardiac & 26 & 35.1 & 4 & 3.2 & & \\
\hline Pediatric & 1 & 1.4 & 29 & 23.0 & & \\
\hline \multicolumn{5}{|l|}{ Years of Experiences } & \multirow{4}{*}{$13.068^{*}$} & \multirow{4}{*}{$<0.001^{*}$} \\
\hline$<5$ & 54 & 73.0 & 59 & 46.8 & & \\
\hline $5-10$ & 16 & 21.6 & 51 & 40.5 & & \\
\hline$\geq 10$ & 4 & 5.4 & 16 & 12.7 & & \\
\hline \multicolumn{5}{|l|}{ Educational level } & \multirow{5}{*}{$17.194^{*}$} & \multirow{5}{*}{$<0.001^{*}$} \\
\hline Secondary nursing school & 0 & 0.0 & 6 & 4.8 & & \\
\hline $\begin{array}{l}\text { Technical institute of } \\
\text { nursing }\end{array}$ & 34 & 45.9 & 26 & 20.6 & & \\
\hline Bachelor of nursing & 40 & 54.1 & 92 & 73.0 & & \\
\hline Master of nursing & 0 & 0.0 & 2 & 1.6 & & \\
\hline \multicolumn{5}{|l|}{ Marital status } & \multirow{3}{*}{$15.129^{*}$} & \multirow{3}{*}{$<0.001^{*}$} \\
\hline Married & 44 & 59.5 & 106 & 84.1 & & \\
\hline Not married & 30 & 40.5 & 20 & 15.9 & & \\
\hline
\end{tabular}

$\chi^{2}$ : Chi square test MC: Monte Carlo

p: $p$ value for association between the studied categories

*: Statistically significant at $\mathbf{p} \leq \mathbf{0 . 0 5}$ 


\section{Tanta Scientific Nursing Journal}

\section{Discussion}

Nurses play important roles in intensive care units because they perform technical nursing care process which includes assessing the patients in life-threatening situations, diagnosing, planning and implementing safe and evidence-based interventions in a timely manner. ${ }^{(41)}$. In patient care, both nursing process and non-technical skills are essential to maintaining optimal practice as well as achieving a high level of expertise ${ }^{(42,43)}$. Non-technical skills are the cognitive and social capabilities that complete the technical skills of health care providers. Social skills include leadership, communication and teamwork, but cognitive skills such as decision-making (44). The result of the current study revealed that more than two- thirds of nurses had satisfied level in performing overall nursing care process. This result may be due to nurses' awareness of the nursing process, the presence of supportive management and the presence of human resources commensurate with the workload as well as clarity with regard to nursing tasks. This result is congruent with Almeida (2019) ${ }^{(45)}$ who found that the nurses presented positive attitudes about nursing process.

Also, Semachew (2018) (46) found that most of nurses have a nursing care process attached with the patients' profile/file. Furthermore, Rahmani et al. (2017) showed that increasing level of satisfaction of nurses when using nursing process. Also, Taskin et al. (2015) ${ }^{(48)}$ found that the most of the nurses had satisfied level in the nursing process stages. As well, Aseratie et al (2014) ${ }^{(49)}$ found that more than half of the respondents were implementing nursing process accurately. On contrary, Agyeman et al. (2018) ${ }^{(50)}$ not supported the present study finding and found that most of nurses were not using the nursing process. Also, Miskir (2018) ${ }^{(51)}$ found that the nursing process was poorly executed in the Afar region.

The finding of the present study revealed that about two -thirds of nurses had satisfied level of total non -technical skills. This result may be attributed to that these skills are actually important tools for performing at work and people with strong non-technical skills are mostly those who are successful in their career. The finding of the present study agreed with Marshall (2018) ${ }^{(52)}$ who found that two -thirds of nurses use non-technical skills to block the error path to address system weaknesses that can lead to negative patient events. Also, Gordon (2015) ${ }^{(53)}$ found that health care professionals are familiar with nontechnical skills. On contrary, Fasoi (2019) 


\section{Tanta Scientific Nursing Journal}

(54) found that that nurses need to learn non-technical skills.

The present study results showed that there were significance correlation between observed nurses' all stages of nursing care process and all domains of non-technical skills.

The finding of the present study is consistent with Ribakova (2018) ${ }^{(55)}$ who found that non-technical skills help to achieve reduction of human errors that could contribute to safety of patients. As well, Peddle (2018) ${ }^{(56)}$ identified that nontechnical skills support patient safety. Also, Pires et al (2016) ${ }^{(57)}$ found that there are evidence of successful outcomes in clinical performance and patient care and safety due to presence of non-technical skills.

Likewise, Myers (2016) ${ }^{(58)}$ found that clinicians ratings for non-technical skills were highly correlated with general performance ratings. Additionally, John (2016) ${ }^{(59)}$ showed that non-technical skills (NTS) were related to successful execution of series of tasks. Furthermore, Riem (2012) (60) and Louis (2012) (61) demonstrated that nursing care process and non- technical skills are related to one another. The present study revealed that there was significant relation between nurses' performance of nursing care process and their characteristics data. The finding of the present study is consistent with Abbas (2017) ${ }^{(62)}$ who found that highly statistical significant association between items which is related to the job performance with age, and educational level. As well as, Hagos (2014) ${ }^{(63)}$ found that from the socio demographic characteristics, only educational status has direct statistically significant relationship with the knowledge of nurses on nursing process.

On contrary, Qtait (2016) ${ }^{(64)}$ found that no correlation between gender, academic degree, experience and nurses performance. Also, Al- Makhaita (2014) ${ }^{(65)}$ found age, gender, and marital status as a personal trait unrelated to performance. The result of the present study revealed that significant positive relation between nurses' non- technical skill and all nurses' characteristics data. This result is congruent with Alaseeri (2019) ${ }^{(66)}$ who found that the nurses' experience had a significant positive effect on the nontechnical skills of the nurses. Nurses' knowledge and educational level certainly affects non-technical skills. The demographics of nurses such as gender, age, and race also affect non-technical skills. Also, Marja (2016) ${ }^{(67)}$ found that many of the participants demographic and work related background factors were slightly associated with several areas of 


\section{Tanta Scientific Nursing Journal}

patient safety skills. Safety skills include non-technical skills such as leadership, teamwork, communication, co-operation, and decision making. As well, Jee (2015) (68) found that age, sex, professional category, marital status, experience and type of ICU were associated with nontechnical skills of nurses.

Furthermore, Kounenou (2011) ${ }^{(69)}$ found that nurses' non-technical skills depending on the educational level of participants, and their participation in life-long learning.

\section{Conclusion}

The results of the study concluded that, more than two- thirds of nurses had satisfied level in performing overall nursing care process. Specifically, the highest mean score is for nursing diagnosis followed by documentation, relation and communication. While, the lowest mean score is for teaching item. As for the nontechnical skills of nurses, less than two thirds of nurses had satisfied level in performing total non -technical skills. Precisely, the highest mean score is for decision making skills followed by communication competence skills, and team dynamic skills. While, the lowest mean score was for leadership behavior skills. The results also showed that there is a positive statistically significant correlation between nurses overall observed nursing care process and their overall non-technical skills.

\section{Recommendations}

\section{For health care organization}

1. Establish and disseminate clear policies to effectively perform clinical practice

2. Provide a suitable number of nursing staff for each unit so that there is no workload or default

3. Provide consumables and machines that facilitate patient care

4. Disseminate the job description for each category of nursing staff so that there is a clear picture of their roles and duties

5. Conduct continuous training to increase nursing skills

6. Provide a safe and orderly environment and give moral and material appreciation to encourage nurses to continue to do good work

\section{For head nurses}

1. Ensure that adequate resources (such as supplies, equipment, and information) are constantly available so that the medical team can provide complete care to patients.

2. Able to successfully resolve conflict and establish positive work place (safety -privacy-support) thus provide an environment based on cooperation, love, communication and problems-free

3. Plan the work to be done and provide sufficient time to meet with the nurses 
when developing a patient care plan to provide nursing with a structured and understandable framework.

4. Develop through continuous research to be up to date so that they can determine what needs to be done to achieve a high quality of healthcare

5. manage time effectively, complete tasks on time, deal with difficult or unexpected tasks without procrastinating, and prepare a daily or weekly list of tasks to do which enables them to finish their work with less effort as time is sword if you do not cut it will cut you

6. Establish the assessment, training and development needs of existing staff nurses to reach the required levels of competence

7. Involve nurses in decision-making and policy making in the unit and improve nursing staff morale by using appropriate supervision method.

8. Strengthen nurses' ability to report their clinical observations and interpretations to the physicians on shift through organizing routine interdisciplinary meetings to enhance accurate and effective dialogue between nurses and physicians on shift.

\section{The nurses}

Nurses in intensive care units are an important and essential resource as they provide care to critically ill patients, and in order to provide the best performance that achieves the desired results, they need to

1. Assess the patient according to the hospital and unit nursing care policies, procedures and standards, and reassess whether there is any change in the patients' health-related behavior

2. Extract the nursing diagnosis from the data collected using critical thinking and past experience. Therefore, nurses must think outside the box and adapt to changing situations.

3. Design a care plan based on the patients' needs, assessment findings and evidence, define the patients' healthcare goal, define the time frame for the care plan, and jointly develop the care plan with patients, families and other healthcare members.

4. Ensure that nursing care is based on the standards of patient care and give priority to nursing care based on an assessment of the patients' condition or immediate needs, and consult experts and competent colleagues in case of any doubts during the implementation

5. Educate the patient and provide clear answers to patients' questions to relieve the patient's tension, convey facts, ideas and opinions to the patient and his 
family, and inform the patient of the places to be followed after discharge

6. Define the time frame for the nursing care evaluation and document the care plan in an understandable and accessible way for all members of the healthcare team.

7. Work to collaboratively resolve disputes, share patient information and any change in their condition with the medical team, and foster positive interactions and future change.

8. Deal with others effectively, feeling the needs of others, and speak in an appropriate and understandable way to patients and their families

\section{Educational level}

Integrate of non-technical skills with nursing care process into undergraduate nursing curriculum.

\section{Further researches need to be conducted} to identify

1. Methods to improve nurses' nontechnical skills.

2. Relation between non- technical skills and patient safety.

\section{References}

1. Mahran G., et al. Challenges and work crisis facing critical care nurses. Egyptian Nursing Journal.2017; 14 (3): 235-241.

2. Sasso G., et al. Cognitive workload of computerized nursing process in intensive care units. Computers, Informatics, Nursing. 2015;

3. RajaeianZ., Masoudi N. Barriers to nursing performance from the perspective of nurses working in intensive care units. Crit Care Nurs J. 2018; 11(1):1-7.

4. Sreenivasan P., Ganganna A., Rajashekaraiah B. Awareness among intensive care nurses regarding oral care in critically ill patients. J Indian Soc Periodontal.2018; 22(6):541-545.

5. Yildiz G. Determining objective data use in intensive care patients' nursing records. International Journal of Caring Sciences.2017; 10 (2):738.

6. Ferreiral R., Montanari F. Development and validation of a nursing care instrument for patients in intensive care unit. Cogitare Enferm.2018; 23(4):1-12.

7. Hagos F. Application of nursing process and its affecting factors among nurses working in mekelle zone hospitals. Nursing research and practice.2014; 9:1-8.

8. Wallace S. The importance of holistic assessment - A nursing student perspective. Nuritinga. 2013; 12:24-30.

9. Cabral1V.Prevalence of nursing diagnoses in an intensive care unit.Rev Rene. 2017; 18(1):84-90.

10. Luzia M. Nursing diagnosis risk for falls: Prevalence and clinical profile of 
hospitalized patients. Rev. Latino-Am.

Enfermagem. 2014; 22 (2):263-268.

Cabral1V.Prevalence of nursing diagnoses in an intensive care unit.Rev Rene. 2017; 18(1):84-90.

11. Abdelkader F. Factors affecting implementation of nursing process: nurses' perspective. IOSR. Journal of nursing and health science. 2017; 6(3): 76-82.

12. Dantas D., Medeiros D. Nursing diagnoses of the domain safety/protection and socioeconomic and clinical aspects of critical patients. Open Journal of Nursing.2016; 6:314322.

13. Akhu-Zaheya L., ,Al-Maaitah R., Bany S. Quality of nursing documentation: Paper- based health records versus electronic- based health records. Journal of clinical nursing. 2018; 27(4):578-589.

14. Kamil H, Wardani E. What is the problem with nursing documentation? Perspective of Indonesian nurses. International Journal of Africa Nursing Sciences.2018; 9: 111-114.

15. Thuvaraka S., Vijayanathan S., Pakeerathy M., et al. Challenges faced by nurses for implementation of nursing process in special units at teaching hospital Jaffna. International
Journal of Science \& Healthcare Research. 2018; 3(1): 61-64.

16. Lima P., Chianca C.,Tannure C. Assessment of nursing care using indicators generated by software. Rev Lat Am Enfermagem. 2015; 23 (2):234-241

17. Simone S. Integrating nurse practitioners into intensive care units. Critical Care Nurse. 2016; 36(6): 5969.18 . Gordon M., Stewart A. Learning health 'safety' within nontechnical skills inter professional simulation education: A qualitative study. Med Educ Online. 2017; 22(1):1-9.

19. Jethro C., Jason Y., Mitchell G. Understanding and assessing nontechnical skills in robotic urological surgery: A systematic review and synthesis of the validity evidence.Journal of Surgical Education .2019; 76(1):193-200.

20. EjimaboN. An approach to understanding leadership decision making in organization. European Scientific Journal.2015; 11(11): 1-24.

21. Khan S. Impact of teamwork on employees' performance. International Journal of Education and Social Science. 2017; 4 (11): 14-22. 
22. ForondaC., WilliamsB. Inter professional communication in healthcare: An integrative review. Nurse Education in Practice (2016); 19: 36-40.

23. Bender., Miriam D. Clinical nurse leader-integrated care delivery: An approach to organizing nursing knowledge into practice models that promote inter professional, team-based care. Journal of nursing care quality. 2017; 32 (3):189-195.

24. Hughes V. Leadership strategies to promote nurse retention. Sci J NursPract. 2017; 1(1): 1-5.

25. HughesV. What are the barriers to effective nurse leadership? Athens Journal of health.2018;5 (1):7-20.

26. Tan Y. The development of skills taxonomy for nursing crisis management. Clinical simulation in nursing. 2018; 25: 6-11.

27. Scott J, Morales D., Riviello R., etal. Non-technical skills and health care provision inlow- and middle-income countries: A systematic review. John Wiley \& Sons Ltd. Medical education. 2016; 50: 441-455.

28. Boet S., Larrigan S., Martin L., et al. Measuring non-technical skills of anesthesiologists in the operating room: A systematic review of assessment tools and their measurement properties. British Journal of Anesthesia, .2018; 121 (6): 1218-1226.

29. Pucher H., Aggarwal R., BatrickN., et al. Nontechnical skills performance and care processes in the management of the acute trauma patient. Surgery (United States).2014; 155 (5): 902909.

30. Leaver M., and Reader W. Nontechnical skills for managing risk and performance in financial trading.Journal of Risk Research.2016; 19 (6):687-721.

31. Khan R, Scaffidi A. Simulation-based training of non-technical skills in colonoscopy: Protocol for a randomized controlled trial. JMIR Res Protoc. 2017; 6(8): 153.

32.Roche F.Human factors and nontechnical skills. Journal of preoperative practice. 2016; 26 (12): 285-288.

33. Poortaghi S, Salsali M, Ebadi A, et al. Findings from a nursing care audit based on the nursing Process: A descriptive study. Nursing and Midwifery Studies. 2015; 4(3):1-6.

34. Ibrahim S, El Sayed R., Attala M, et al. Relationship between head nurses' leadership styles and staff nurses' job performance .IOSR Journal of Nursing and Science $2016 ; 5(1): 66-74$. 
35. Soares M. Competence-based performance evaluation in hospital nurses. Rev. Latino-Am. Enfermagem [online]. 2019; 27: 1-8.

36. Cooper S, Endacott R, and Cant R. Measuring non-technical skills in medical emergency care: a review of assessment measures. Open Access Emergency Medicine OAEM. 2010; 2: 7-16.

37-Enzinger I .Teamwork perceptions of nurses and nursing assistants in a community hospital. The walden dissertations and doctoral studies collection at scholar works.2017; 6062.

38-Stinson K. The ties that bind: the relationships between and among registered nurses' clinical experience, clinical decision-making processes, and nursing practice issues related to physical restraint use with attitudes toward the use of physical restraints in the critical care environment. Seton hall university dissertations and theses.2013; 120-124.

39. Larsson I, and Sahlsten M. The staff nurse clinical leader at the bedside: swedish registered nurses' perceptions. Nursing Research and practice. 2016; 2-3.

40. Morsy S. Relation between time management skills and effective delegation among the head nurses at assuit

university hospitals.AAMJ.2010; 8(3):33-34

41. Woo B., Lee J., Tam W. The impact of the advanced practice nursing role on quality of care, clinical outcomes, patient satisfaction, and cost in the emergency and critical care settings: a systematic review. Hum Resour Health. 2017; 15(1):63.

42. MollK., Kamphausen A., Hampe W, et al. Anaesthesiology students' NonTechnical skills: Development and evaluation of a behavioural marker system for students (AS-NTS). BMC Med Educ.2019; 19(205):2-11.

43. Collins W., Dell P., Hung J a., Brook R. The importance of technical and non-technical skills in robotic surgery training. Eur Urol Focus.2018; 4(5):674-676.

44. Brunckhorst O., Khan S., Dasgupta P. Non-technical skill training and the use of scenarios in modern surgical education. Curr Opin Urol.2017; 27(4):330-336. Res Pract. 2018; 2018:2-6.

45. Almeid A., Beatriz P. Attitudes of nurses from a public teaching hospital regarding the nursing process. Rev. esc. enferm. USP [online]. 2019; 53:1-8.

46. Semachew A. Implementation of nursing process in clinical settings: the case of three governmental hospitals in 
Ethiopia. BMC Res Notes. 2018; 11(1):173.

47. Rahmani M., Davarpanah M., Naseri M., et al. The effect of nursing process implementation using "accessible care cards" method on satisfaction rate of nurses, patients and parents of inpatient children of care manner. International Journal of Medical Research \& Health Sciences, 2017, 6(9): 121-130.

48. Taskın F., Sabanciogullari S., Aldemir $\mathrm{K}$. The opinions of nursing students regarding the nursing process and their levels of proficiency in turkey. $\mathrm{J}$ Caring Sci. 2015;4(4):265-275.

49. AseratieM., Murugan R., Molla M. Assessment of factors affecting implementation of nursing process among nurses in selected governmental hospitals, Addis Ababa, Ethiopia; Cross Sectional Study .J Nurs Care. 2014; 3(3):2-8.

50. AgyemanY., Korsah K. Nonapplication of the nursing process at a hospital in Accra, Ghana: lessons from descriptive research. BMC Nurs. 2018; 17(45); 2 - 7.

51. Miskir Y., Emishaw S. Determinants of nursing process implementation in north east ethiopia: Cross-Sectional Study. Nurs. 2018; 27(7):1475-1487
52. Marshall C., Finlayson P. Identifying the nontechnical skills required of nurses in general surgical wards. J Clin

53. GordonM., Box H., Halliwell J., et al. Enhancing health care non $\neg$ technical skills: the TINSELS program me. Clinical Teacher, 2015; 12 (6):413$\neg 417$.

54. Fasoi G., Bourazani M., Kelesi M. Non-technical skills for nurseanesthetists: learning and evaluation. World journal of pharmaceutical and medical research. 2019; 5(9): 1-8.

55. Ribakova A ., Liana D. Assessment of non-technical skills of operating room nurses. 6th international interdisciplinary scientific conference society. health. welfare (part ii) .2018;51:9.

56. Peddle M., BearmanM., Radomski N., et al. What non-technical skills competencies are addressed by Australian standards documents for health professionals who work in secondary and tertiary clinical settings? A qualitative comparative analysis. BMJ Open.2018; 8:1-9.

57. Pires S., Monteiro S., Pereira A., etal. Non-technical Skills in undergraduate nursing education: Consideration for a Training Course Development. Rev. 
Latino-Am. $\quad$ Enfermagem.2016; 26:311-319.

58. Myers A., Powell M, Psirides A., etal. Non-technical skills evaluation in the critical care air ambulance environment: introduction of an adapted rating instrument--an observational study. Scand J Trauma

Saudi Arabia: a comparative study. International Journal of Medical Science and Public Health. 2014; 3: 10.

59. John S., Dianali M., Andrew M., et al. Non-technical skills and health care provision in low- and middle-income countries: a systematic review. John Wiley \& Sons Ltd. Medical education 2016; 50: 441-455.

60. RiemB., BouldM., TavaresW. Do technical skills correlate with nontechnical skills in crisis resource management: a simulation study. British Journal of Anesthesia.2012; 109 (5)723-728.

61. Louise H., Sonal A., Rajesh A The impact of nontechnical skills on technical performance in surgery: a systematic review. $\mathrm{PhD} \mathrm{J}$ Am Coll Surg 2012; 214:214-230.

62. Abbas A. Impact of job satisfaction on job performance of nurses at alsuwaira general hospital. The iraqi national journal of nursing specialties. 2017; 30(2)73-82.

63. Hagos F., Alemseged F., Balcha F., et al. Application of nursing process and its affecting factors among nurses working in mekelle zone hospitals, northern ethiopia. Nurs Res Pract. 2014; 2014: 675212.

64. Qtait M., Sayej S. Demographic variable (age, gender, qualifications, income) and effecte i n Nurses' Performance in Hebron Hospitals. Journal of Health, Medicine and Nursing.2016; 24:89-98.

65. Al-Makhaita H., SabraA ., HafezA. Job performance among nurses working in two different health care levels, Eastern

66. AlaseeriR., Aziza R., Maram B. Factors influencing nurses' decisionmaking process integrative literature. OSR Journal of Nursing and Health Science (IOSR-JNHS).2019.8(4):36-48

67. MarjaK., Arvydas M. Health care professionals' skills regarding patient safety.Medicina.2016; 52(4): 250-256.

68. JeeD., Jeonghoon D. Teamwork and clinical error reporting among nurses in korean hospitals. Asian nursing research.2015; 9(1): 14-20.

69. KounenouK., Koutra A., Koumoundourou G. Nurses' communication skills: exploring their relationship with demographic variables and job satisfaction in a Greek sample. Procedia - Social and Behavioral Sciences 2011; 30: 2230 - 2234. 